\title{
Virtual Civil Society in the United States and Australia
}

\author{
Russell J. DALTON \\ University of California, Irvine \\ Miki Caul Kittilson \\ Arizona State University
}

\begin{abstract}
Although many scholars agree that social interactions within traditional social groups build social capital, there is less consensus on the benefits of virtual interactions on the Internet. The authors compare the activity of Americans and Australians based on a common battery of social network interaction questions. Their findings suggest that virtual social interactions foster many of the same positive social capital traits for citizenship norms and political participation that are produced by traditional in-person social networks. Thus social networking and virtual interaction have the potential to generate new stocks of social capital in contemporary democracies.
\end{abstract}

Keywords: citizenship norms; civil society; Internet; political participation; social capital; social networks; virtual interaction

Will a shift from in-person association to virtual association undermine the production of norms, attitudes and behaviours that underpin stable and effective democracy? Some studies have described a recent decline in social group engagement in the US and other established democracies, and with it concomitant erosion in civic norms and political participation. For instance, Putnam (2000) argued that memberships in fraternal groups, religious activities, union activities, and a host of other social associations have declined markedly since the 1970s. This has produced dire forecasts about the vitality of American society and democracy because of the presumably negative consequences of declining social capital (Macedo et al. 2005). Andrew Leigh (2010) pointed to a similar downward trend in social group participation in Australia (see also Cox 2002; McAllister 2011, Chapters 5 and 6; cf. Stone and Hughes 2002).

Conversely, other research suggests that while participation in traditional membership groups may wither, the ways in which people interact evolve over time, creating new forms of social engagement. Viewed through a longer-term

Russell J. Dalton is Professor of Political Science at the University of California, Irvine. Miki Caul Kittilson is Associate Professor of Political Science at Arizona State University. 
historic lens, the halcyon days of fraternal lodges, bowling leagues and choir/ choral societies have passed. Older types of social organisations based within communities have given way to newer types of social connections and more fluid connections through other voluntary networks and self-help groups. These new interactions are often not connected with a national umbrella group or even formal membership rolls, making the measurement of involvement more difficult.

In addition, technological innovations may be changing the ways in which people associate with one another. In 2010, 79 per cent of American adults reported using the Internet (Hampton et al. 2011) as did 75 per cent of Australian adults, according to the 2007 Australian Election Study. The socalled Web 2.0 offers new opportunities for social interactions through social networking sites, chat rooms, online multiplayer games, blogs, and other virtual activities. These new technologies have the potential to expand the amount of social interaction that individuals pursue through the Internet. As these developments were unanticipated by early critiques of the social capital potential of the Internet, a reappraisal is necessary.

Our research asks whether these new forms of virtual social interaction can benefit social capital formation in ways similar to traditional social group activity. Based on surveys of the US and Australian publics, we examine whether Internet-based social interactions contribute to two dimensions of social capital: citizenship norms and political involvement. These surveys include a common battery of questions measuring Internet-based interactions, coupled with a range of potential social capital effects.

This research has important implications for debates over the decline in social capital in advanced industrial democracies. Although participation in traditional associations may be waning, interactions on the Internet are rising rapidly. The Internet is also the domain of the young, and thus might counter the more rapid decline in traditional group activity among youth. Evidence that virtual interactions foster democratic norms and activities would offer a more positive view of current trends in the stores of social capital. And despite political, economic and technological similarities, there are important contrasts between electoral systems, party systems and political culture that might affect political engagement in Australia and the US. Given this contrast, finding evidence for similar relationships between virtual interactions and democratic engagement for both countries would point toward the robustness of these findings.

\section{A Virtual Civil Society}

The linkage between associational life and social capital has a long history in social science research, and so we will only briefly summarise this literature. Scholars maintain that the norms of good citizenship, shared trust and reciprocity that make up social capital are rooted in interpersonal interactions (Howard and Gilbert 2008; Putnam 1993, 2000; Uslaner 1998). Civil society activity also should develop the norms of civic engagement, such as the belief in an active citizen role. Participation in civil society groups can produce social and organisational skills that are vital for a participatory democracy - much in 
the tradition of Tocqueville's image of democracy in America. Development of these citizenship norms and skills is the prime argument of social capital theory.

Technological advances in the past decade have generated significant changes in communication styles among individuals, which may increase the potential of generating social capital through virtual interactions. The early Internet offered limited social contact, often with a unidirectional flow of information from website to user. Today, a new style of Internet activity offers substantially more opportunities for interaction. Many people join social groups through the Internet, receive e-newsletters from their groups or visit group websites, or receive and respond to postings from Twitter. Cyber associations have expanded rapidly as individuals interact through social networking sites, online forums, chat rooms and online simulations. In 2010, fully 59 per cent of Internet users in the US frequented social networking sites such as Facebook, LinkedIn or MySpace (Hampton et al. 2011).

Research on Internet interaction yields mixed results on its potential role in fostering the norms of citizenship and participation in politics. Several scholars have suggested that social capital formation requires face-to-face networks. For instance, Putnam, Feldstein and Cohen (2003, 9) concluded that 'our investigations strongly suggest that trust relationships and resilient communities generally form through local personal contact'. Supporting this point, several early empirical studies of Internet users suggested a negative or limited role for the Internet in linking citizens together (Kraut et al. 1998; Nie and Erbring 2002). Even Leigh's (2010) recent Australian study is sceptical that virtual interactions and social networking can enhance social capital, although his empirical evidence is limited.

Many Internet studies, however, examine the simple extent of Internet usage without regard to the nature of the usage. Simple undifferentiated measures of Internet usage are less relevant to social capital formation than how citizens are using the Internet today. Consequently, recent research suggests that because new types of social networking encourage the flow of information and social interactions, this may develop the norms and skills of good citizenship (Baumgartner and Morris 2009; Ellison, Steinfeld and Lampe 2007; Hampton et al. 2011; Jennings and Zeitner 2003; Valenzuela, Park and Kee 2009). Virtual associations can facilitate collecting and exchanging information, and allow members to make up their own minds on issues. In this way, virtual associations may develop skills in critical analysis. There is even evidence that participation in massive online role-playing games may foster information-seeking and interpersonal skills (Jenkins 2006). Internet social interactions of various sorts may give users more time to reflect, collect information and offer greater control over their responses than through live conversation; they may allow freer exchange of viewpoints (Ho and McLeod 2008; McKenna and Bargh 2000).

Significantly, a series of studies by Robert Kraut and colleagues suggest dynamic effects of Internet use over time. Kraut et al. (1998) originally reported negative effects of Internet use for social involvement for a sample of Americans. However, a follow-up panel study (Kraut et al. 2002) found that those same Internet users increased the size of their local and distant social circles over time, gained more face-to-face interaction with friends and family, greater community activity and more social trust - Kraut et al. $(2002,68)$ credit changes in the Internet itself for this shift. 
More specific to our interests, several studies demonstrate that Internet use is associated with higher levels of political participation. Research suggests that various aspects of Internet usage are related to levels of civic participation (Jennings and Zeitner 2003; Shah et al. 2002; Tolbert and McNeal 2003). The Pew 2008 Internet and Social Engagement survey also found a modest positive relationship between using a social networking site and conventional political activity among Americans (Curtice and Norris 2007 for Britain; Smith et al. 2009). A recent Pew study of social networking found that Facebook users had a higher level of social trust than non-users (Hampton et al. 2011).

Another significant feature about virtual social activity is the potential to promote social and political engagement amongst youth, who have typically displayed the greatest drop-off in traditional social group activity (Putnam 2000). Use of Facebook and other social networking sites primarily remains the domain of the young, even if their elders are beginning to use this new medium. Research specific to social networking among young people demonstrates that sites such as Facebook facilitate new and previous face-to-face relationships and enhance political participation, civic engagement, social trust and overall life satisfaction (Ellison, Steinfield and Lampe 2007; Valenzuela, Park and Kee 2009). If virtual social interaction is a method to develop social capital, then this may fill the void created by the decline of traditional social group membership among the young.

Other studies are less sanguine about the positive impact of Internet use on political participation (Baumgartner and Morris 2009; Krueger 2002). Thus, a meta-analysis of 38 studies reveals that the Internet has few negative consequences for political engagement, but suggests that further research is needed to assess whether the Internet plays a positive role (Boulianne 2009).

Our research builds upon these past studies while offering several advances. First, instead of measuring only undifferentiated Internet usage, we explicitly examine social interactions via the Internet. Early empirical studies comparing Internet users and non-users may have underestimated the actual effects of virtual civil society in the new environment of social networking sites and online communities.

Second, we link Internet-based social interaction to political participation. We examine whether virtual social networking increases political norms such as feelings of political efficacy and political engagement similar to the relationship for traditional face-to-face interactions. Then we examine the impact of virtual interaction on a variety of political activities from participation in elections to collective actions to protest activity. We use a multivariate model in an attempt to limit the endogeneity problem of survey responses, controlling for other potential causal effects.

Third, we examine this topic across two established democracies - the US and Australia - that share many democratic traits but also differ significantly in other areas. The contrast between compulsory voting and the ATV (alternative transferable vote) electoral system in Australia, and the low turnout in a diffuse SMD (single-member district) system in the US may affect overall levels of electoral participation; Australia has a relatively strong party system, while the US's is diffuse and decentralised. Variations in broadband access and other social conditions may influence social networking patterns and their consequences. Assessing how virtual interaction relates to political engagement 
should improve our understanding of the mechanisms that generate social capital, and how these may be changing in advanced industrial democracies.

\section{Measuring Virtual Civil Society Activity}

A substantial part of Internet activity can involve impersonal activities such as ordering from a catalogue or looking up information. Yet, the Internet also opens a virtual door to a vast array of interpersonal interactions. These range from social networking sites, to contributing to online forums, to collaborating in Internet communities (such as online multiplayer games and other communities). Explicit political activity on the web is less common (such as discussion groups on political websites or connecting to like-minded citizens). The civil society thesis, however, holds that social interactions - even in non-political social groups or perhaps non-political web groups - can produce social capital. We are fortunate to have two national surveys that measure virtual civil society activity.

The 2005 'Citizenship, Involvement, Democracy' (CID) survey of the Centre for Democracy and Civil Society (CDCS) examined the political values and behaviours of the American public. ${ }^{1}$ The 2007 Australian Election Study (AES) surveyed respondents on a broad range of political topics. ${ }^{2}$

To measure participation in virtual civil society, the two surveys focused on social interactions that occur over the Internet. The CID asked seven questions:

Q. 7. Please tell how much, if at all, the Internet has helped you do each of the following things? How about (READ ITEM). Would you say a lot, some, only a little, or not at all?

a. Become more involved with groups and organisations you already belong to

b. Interact with people or groups who share your hobbies or interests

c. Interact with people or groups who share your religious beliefs

d. Interact with people or groups who share your political views

e. Interact with people of a different race from yours

f. Interact with people of different ages or generations

g. Interact with people from other countries

The AES included an item on interaction with family and friends that we do not consider because it is not available for both nations. The advantage of this battery is that it does not just measure the amount of time spent on the Internet,

\footnotetext{
${ }^{1}$ The nationally representative CID survey conducted in-person interviews with 1,001 respondents between 16 May and 19 July 2005. International Communications Research did the interviews using a clustered, area-probability sample of households and random selection of respondents. We appreciate the assistance of Marc Howard and CDCS in providing access to these data. Additional information on the survey is available from the project website: http:// www.uscidsurvey.org/.

${ }^{2}$ The 2007 AES surveyed 1,873 adults through a postal survey conducted by Ian McAllister, Clive Bean, Rachel Gibson and David Gow. These data and additional information on the survey are available through the Australian Social Science Data Archive at the Australian National University: http://www.assda.edu.au/.
} 
but focuses specifically on virtual social interactions. ${ }^{3}$ As with traditional social group membership, this battery includes virtual interactions in various social settings that are typically not political - the exact phenomenon that is central to the social capital thesis.

Table 1 illustrates the diverse pattern of Internet activity. As a baseline, a substantially larger number of Americans (43 per cent) in 2005 report having no Internet access or never using the Internet as compared to a quarter of Australians in 2007 (24 per cent). We suspect that part of this cross-national difference is because of the timing of the surveys, with virtual social networking dramatically growing during the 2000 s. $^{4}$

The first four items tap what might be called bonding social networks: existing group members, fellow hobbyists, co-religionists, or those sharing a political view. Australians are slightly more likely to say that the Internet helps them 'a lot' or 'somewhat' to become more involved in existing groups and interact with people sharing their hobbies. Despite the lower level of reported Internet access among Americans, they are actually slightly more likely to say they interact online with those who share their religious or political beliefs. This probably reflects the greater centrality of religion in American life and a more extensive politicisation of the average citizen.

The Internet also facilitates social networks that broaden interactions beyond the immediate community and existing social networks. Web activity often starts as a colour-blind and gender-blind medium, so people of different races or genders can interact without first knowing each other's identity. Thus, three items tap bridging interactions: with people of a different race/ethnicity, age or country. Americans generally report more virtual social interaction than Australians for racial and age-based interactions. Australians report more interaction with people from a different country. Australians are also more likely than Americans to travel internationally and have ties to relatives in other nations, which may increase international connections.

We summarise virtual social activity by counting the number who say they use the Internet 'a lot' or 'somewhat' for each type of activity. ${ }^{5}$ Table 2 presents the distributions on this index for the overall population and only for Internet users. Most Americans report no Internet interactions (61 per cent), but the majority of this group lack access to the Internet or are non-users. Among the overall public 17 per cent report interacting in four or more of the Internet options. Reports of virtual interactions are substantially greater among Americans who have access to the Internet (the second data column in the

\footnotetext{
${ }^{3} \mathrm{We}$ are sceptical of previous research that uses simple measures of the amount of Internet usage as a predictor, without determining what is done on the Internet; participating in a chat room seems more analogous to social group activity than does ordering a book from Amazon.com. ${ }^{4}$ For instance, the percentage of Americans who report using a social networking site has grown from 8 per cent in February 2005 to 29 per cent in May 2008 (Pew Research Centre 2010). So our two surveys separated by several years may yield inaccurate cross-national comparisons on levels of Internet activity. The World Values Survey polled about Internet usage as an information source and found that Americans in 2006 reported higher usage (6 per cent) than Australians polled in 2005 (5 per cent) (World Values Survey).

${ }^{5}$ The first column presents the count of the number of interactions that were done 'often' or 'sometimes'. Those who did not have access to the Internet at home or at work are included in the 'none' category in this column. The 'none' group is deleted in the next column of Internet users.
} 


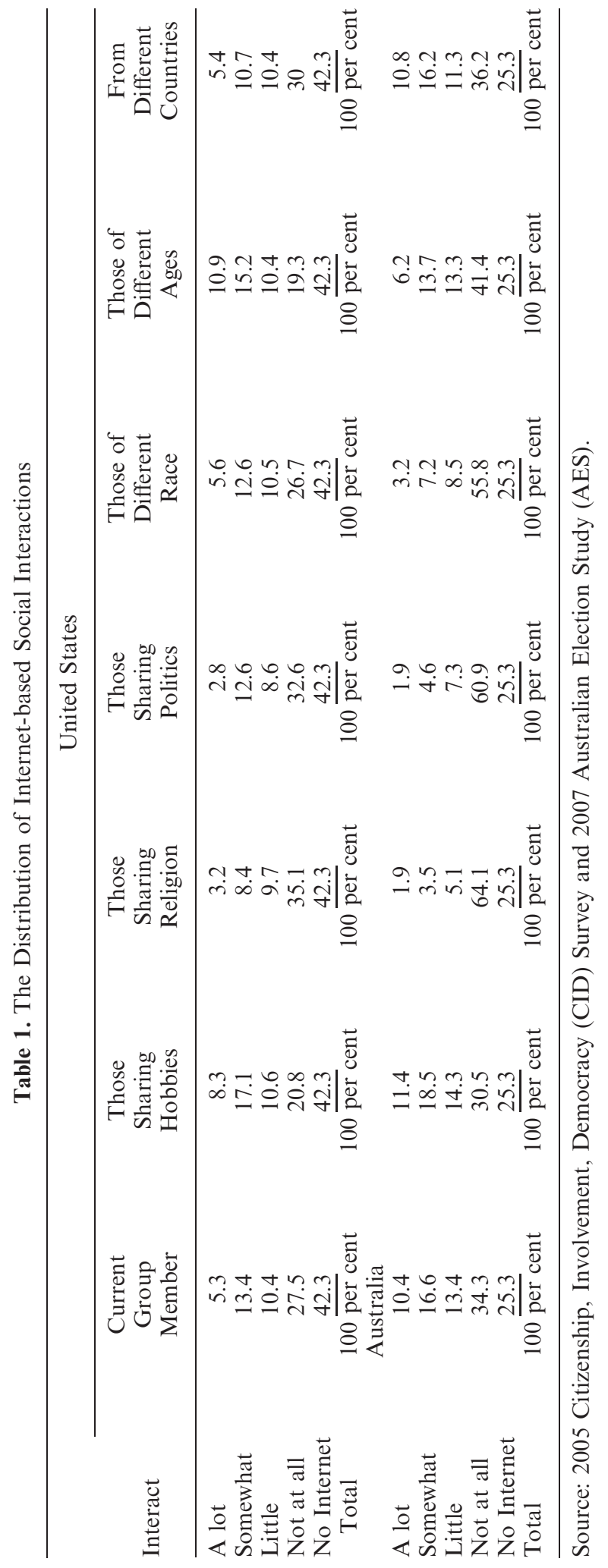


Table 2. Overall Internet-based Interaction

\begin{tabular}{|c|c|c|c|c|}
\hline \multirow[b]{2}{*}{ Number } & \multicolumn{2}{|c|}{ United States } & \multicolumn{2}{|c|}{ Australia } \\
\hline & $\begin{array}{c}\text { Virtual Social } \\
\text { Activity }\end{array}$ & $\begin{array}{c}\text { Virtual Social } \\
\text { Activity (Internet } \\
\text { Users) }\end{array}$ & $\begin{array}{l}\text { Virtual } \\
\text { Social } \\
\text { Activity }\end{array}$ & $\begin{array}{c}\text { Virtual } \\
\text { Social Activity } \\
\text { (Internet Users) }\end{array}$ \\
\hline Six or more & 6.2 & 8.4 & 3.2 & 4.4 \\
\hline 5 & 5.5 & 7.5 & 3.3 & 4.6 \\
\hline 4 & 5.3 & 7.1 & 6.5 & 9.1 \\
\hline 3 & 5.7 & 7.7 & 7.9 & 14.8 \\
\hline 2 & 7.2 & 9.7 & 10.6 & 14.8 \\
\hline 1 & 8.9 & 12.0 & 11.7 & 16.3 \\
\hline None & 61.1 & 47.6 & 56.9 & 39.7 \\
\hline Total & $100 \overline{\text { per cent }}$ & $100 \overline{\text { per cent }}$ & $100 \overline{\text { per }}$ cent & $100 \overline{\text { per cent }}$ \\
\hline Mean & 1.28 & 1.73 & 1.18 & 1.65 \\
\hline$(\mathrm{N})$ & (1001) & $(744)$ & (1873) & (1334) \\
\hline
\end{tabular}

Note: Table entries are percentages in each column, with the mean and $\mathrm{N}$ for each column. Because of the small percentages, those with six or seven interactions were collapsed to six or more in this table and subsequent analyses.

Source: 2005 CID Survey and 2007 AES.

table). A plurality still report no interactions, but 23 per cent report four or more connections.

The next two columns present the comparable results from Australia. Although many more Australians used the Internet in 2007, the percentage reporting four or more interactions (13 per cent) is slightly lower than in the US. Controlling for Internet usage, Australians' contacts are slightly lower than Americans'.

Virtual civil society represents a new style of social engagement that draws different people into social activity. As we expected, virtual civil society activity is predominately the domain of the young (Figure 1). Young Australians average almost three types of online interaction, while those over 70 average about a tenth of one Internet activity. Australian age differences $(r=-.38)$ are even greater than across American age groups $(r=-.23)$. This may reflect the special appeal of the Internet to young Australians, or the time lag between surveys when social networking activities were rapidly expanding.

When age is combined with education, this clearly identifies the core of virtual civil society. Among young, university-educated Americans, 73 per cent have some Internet interactions, while the comparable percentage among all older Americans (regardless of education level) is just 15 per cent. Among young, college-educated Australians, the comparable group is 92 per cent with some Internet interactions. The young are the wired generation, who interact through social networking sites, texting and Twitter - while their parents are attending a church social, a book club or a Pilates class. The question is whether this new form of virtual social interaction has the same social capital effects.

\section{The Correlates of Civil Society Activity}

The essence of the Tocquevillian model of democracy is that civil society interactions breed democratic habits of the heart. Although the specific survey 


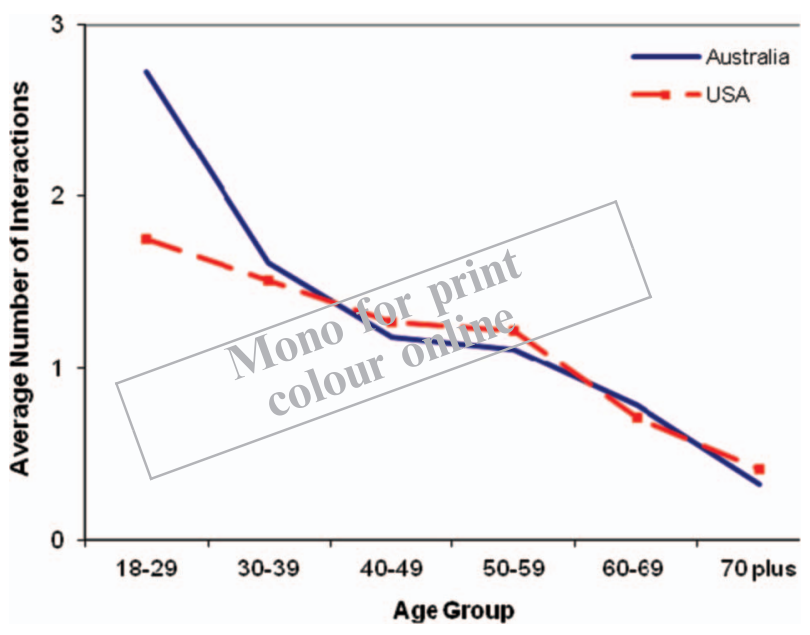

Figure 1. Age Differences in Virtual Social Activity.

Note: Figure entries are mean scores on the index of virtual social activity for entire public (Table 2) by age group.

Source: 2005 CID Survey and 2007 Australian Election Study.

questions differ, there are three areas where the content of the US and Australian surveys overlaps on attitudes that are typically linked to the social capital literature: social trust, feelings of political efficacy, and norms of participatory citizenship. We examine these bivariate relationships in this section. Then, for the more extensive battery of political participation questions, we develop a multivariate model to control for other factors that might produce spurious bivariate relationships.

\section{Civic Norms}

Researchers have stressed that one of the prime effects of civil society participation is a potential for increasing trust of others (Newton 1997; Putnam 2000; Uslaner 2002). Social trust is important in supporting collective efforts, developing feelings of reciprocity, and lessening the barriers to cooperation in order to overcome collective action problems. This is supposedly a central consequence of civil society participation. As Putnam noted: 'Social networks allow trust to become transitive and spread' (1993, 169). Virtual interactions may similarly engender trust, although the nature of online interactions proves important (Shah, Kwak and Holbert 2001).

The first row of Table 3 presents the correlations between virtual social interactions and the standard social trust question. ${ }^{6}$ There are weak positive correlations with virtual civil society activity in both nations, although both correlations are in the correct direction. Nonetheless, we should judge these relationships relative to other predictors. In other analyses we showed that the relationship between social trust and participation in face-to-face groups is only

\footnotetext{
${ }^{6}$ Gibson and McAllister (2009) analyse virtual interactions and social trust in Australia. The US survey coded trust in terms of a 10-point scale, and the Australian survey used a dichotomous response. However, the stem of both questions was very similar.
} 
Table 3. Correlations of Virtual Social Activity and Social Norms

Social-political Norms USA

Social Trust: can trust others

Efficacy: can understand politics

Engaged Citizenship Index
Social-political Norms Australia

$\begin{array}{lll}.05 & .09 * & \text { Social Trust: can trust others } \\ .12 * & .02 & \text { Efficacy: people who vote can make a difference } \\ .21 * & .18^{*} & \text { Post-material: Participation Norms }\end{array}$

Note: Table entries are Pearson $\mathrm{r}$ correlations between virtual social activity and social-political norms.

Source: 2005 CID Survey and 2007 AES.

slightly stronger in the US survey. ${ }^{7}$ Rachel Gibson and Ian McAllister (2009) found similar relationships with the 2007 AES survey, focusing on the differential effects of bonding versus bridging virtual interactions.

Another potential consequence of civil society activity is the nurturing of feelings that one can manage the affairs of life, which could expand to feelings that the individual could be politically efficacious or should be politically engaged (Putnam 1993, 86-7). If one could organise a church bazaar or a school activity, this might foster beliefs that carry over to the political domain. In other words, civil society activity stimulates the norms of citizenship that may encourage political participation. The American CID survey asked a standard question of whether politics is too complex for the respondent to understand; the efficacious citizen would disagree with this statement. The AES included a question on whether voting can make a difference; the efficacious citizen would agree. Single items are not ideal, and these are different items, but they both tap what is commonly described as feelings of internal political efficacy.

The second row in Table 3 shows that virtual social activity is positively related to both efficacy questions, although the Australian correlation is not statistically significant. The US results, at least, are meaningful because they imply that virtual interaction of a largely apolitical nature is nonetheless positively related to political norms.

A third potential consequence of civil society activity is a belief that a 'good' democratic citizen should participate in the political process (Dalton 2009). If civil society participation nurtures positive habits of the heart that sustain democracy, they may be more apparent in such broad measures of citizenship norms (van Deth, Montero and Westholm 2007; Zmerli 2010). At question is whether these norms are also related to virtual social interactions.

The CID survey asked a battery of questions on the qualities of good citizenship. Dalton (2009) developed an index of engaged citizenship based primarily on items such as the importance of forming one's own opinion, being active in politics, being active in voluntary groups, and supporting those who are worse off. ${ }^{8}$ The AES incorporated Inglehart's (1990) 12-item post-material

\footnotetext{
${ }^{7}$ Kittilson and Dalton (2008) find that social trust is also weakly correlated with a count of the number of social group memberships (.14) and a count of the number of groups in which the respondent participates (.10).

${ }^{8}$ This is the standardised factor score for the second dimension of engaged citizenship based on a factor analysis of all the citizenship items in the survey. See Dalton (2009, 27-9). The first
} 
values battery. We use these questions to create an index of post-material values that has a heavy participatory emphasis. ${ }^{9}$ We expect that virtual interactions might foster both participatory norms and the broader social concerns reflected in these indices.

The last row of Table 3 shows that virtual interactions are strongly related to the index of engaged citizenship among Americans as well as post-material values among Australians. It thus appears that interacting with others - even if online - contributes to the development of social and political norms that are essential parts of social capital. Social networking can foster social trust, feelings of efficacy and participatory norms even if face-to-face contact is limited.

\section{Political Participation}

A long series of analyses predicts that membership of traditional social groups bolsters political involvement, both in the US and across advanced industrial democracies (Cox 2002; Norris 2002a; Putnam 2000; Verba, Schlozman and Brady 1995). Virtual interactions may encourage political involvement through similar mechanisms of stimulation and mobilisation. We thus expect a positive relationship of virtual activity with various forms of political participation.

Both surveys asked questions on general interest in politics and the frequency of political discussion. The CID survey is exceptional because it also asked respondents whether they had participated in 15 different types of political activity over the past year, including voting in the 2004 election. These items reflect four broad dimensions of participation: direct action, electoral activity, Internet activity, and protest activity. ${ }^{10}$ The 2007 AES contains 10 participation items, with five tapping aspects of electoral participation and five on nonelectoral participation. The content and the wording of the items are different across nations, but the similarity of concepts should produce broadly comparable analyses.

Table 4 shows the relationship of virtual social activity with each item organised into participation categories. Almost all of the correlations in Table 4 show a statistically significant positive relationship between virtual social interactions and different examples of participation. General political engagement, measured by political interest and frequency of political discussion, has statistically significant relationships in both nations. The two studies overlap in their examples of direct forms of political action: signing a petition, contacting a politician or working with a group. These participation activities display moderate to strong relationships with virtual social activity, especially in the US

dimension of duty-based citizenship is unrelated to virtual interactions $(r=-.03)$ and social group membership $(r=.03)$.

${ }^{9}$ The AES included the Inglehart (1990) 12-item value index. We counted the number of postmaterial items mentioned as first- or second-most important: give people more say in government decisions, protect free speech, people have more say about their jobs, progress toward a more humane society, and progress toward a society where ideas count more than money. The index ranges from $0=$ no items to $5=$ mentioned all five.

${ }^{10}$ Kittilson and Dalton (2011) measured four separate dimensions of participation and analysed each dimension separately. 
Table 4. Correlations of Virtual Social Activity with Political Participation

US Political Participation

Interest in politics

Discuss politics

\section{Direct Action}

Sign a petition

Contact a politician

Work for other political group

Display political sticker/banner

Donate money to group

Boycotting a product

Bought a product for ethical, political reasons

\section{Electoral Politics}

Vote

Work for a political party or action group

Work for a political campaign
Australian Political Participation

$\begin{array}{lll}.17^{*} & .05^{*} & \text { Interest in politics } \\ .23 * & .20^{*} & \text { Discuss politics during } \\ & & \text { election }\end{array}$

Direct Action

$.27^{*} \quad .16^{*} \quad$ Signed a petition

$.21^{*} .11^{*} \quad$ Contact politician or government official

$.21 * \quad .17 * \quad$ Work with people on shared concern

$.22 *$

$18^{*}$

$.20^{*}$

$.24 *$

\section{$.12 *$ \\ $.19^{*}$ \\ $.17 *$}

$.16^{*}$ Persuade others how to vote

$.15^{*}$ Go to campaign meetings

$.11^{*}$ Show support for party or candidate

$.08 *$ Contribute to campaign or candidate

Internet Participation

Internet Participation

Forward electronic message with political content

Participate in Internet political activities

Visit website of political organisation

$.29 *$

$.29 *$

$.35^{*}$

\section{Protest Politics}

Attend lawful demonstration

Illegal demonstration

\section{Protest Politics}

$.16^{*} .18^{*} \quad$ Take part in protest, march

Summary participation index

$.38 * \quad .28 * \quad$ Summary participation index

Note: Table entries are Pearson $r$ correlations between the index of virtual civil society activity political participation and for entire public. Correlations with asterisk are significant at $p<.05$. Source: 2005 CID Survey and 2007 AES.

survey. Virtual interactions are strongly related to two measures of political consumerism in the American survey and to the examples of electoral activity in both nations, although the latter relationships are somewhat weaker. As we should expect, virtual social interactions are most strongly correlated with Internet-based activity. Forwarding a political email or participating in Internet-based political activities both yield a .29 correlation among Americans. Signing an electronic petition produces a .27 correlation for Australians. Finally, virtual social interaction is related to lawful protest activity in both nations. 
To illustrate the general impact of virtual social activity on political participation, we create a summary participation index in both nations. ${ }^{11}$ This participation index is listed in the last row of Table 4 and shows a substantial correlation in both the US (.38) and Australia (.28). To provide more insight into the strength of these relationships, Figure 2 plots the participation index scores by the amount of virtual social activity. The strong relationships are clearly apparent. Those with little online activity have below-average overall participation in both nations. Overall activity then steadily increases with levels of virtual social activity.

It is difficult to make exact comparisons across nations in Table 4 because the surveys asked somewhat different questions. Yet, a positive relationship between virtual social activity and political participation clearly exists in both nations. Indeed, the consistent positive relationships across two nations with different examples of political participation and differently worded questions speak to the robustness of these patterns. The commonality of the crossnational patterns speaks to the potential generalisability of these results. Despite differences in Internet usage, norms toward political participation, and the political histories of both nations, virtual social activity has the same participation consequences for Americans and Australians.

While some have opined that time spent in front of laptop screens or smartphones will distract people from more serious pursuits - such as politics the evidence here points in the opposite direction. Social activity in a virtual world seems to carry the same benefits in inculcating skills and norms leading to

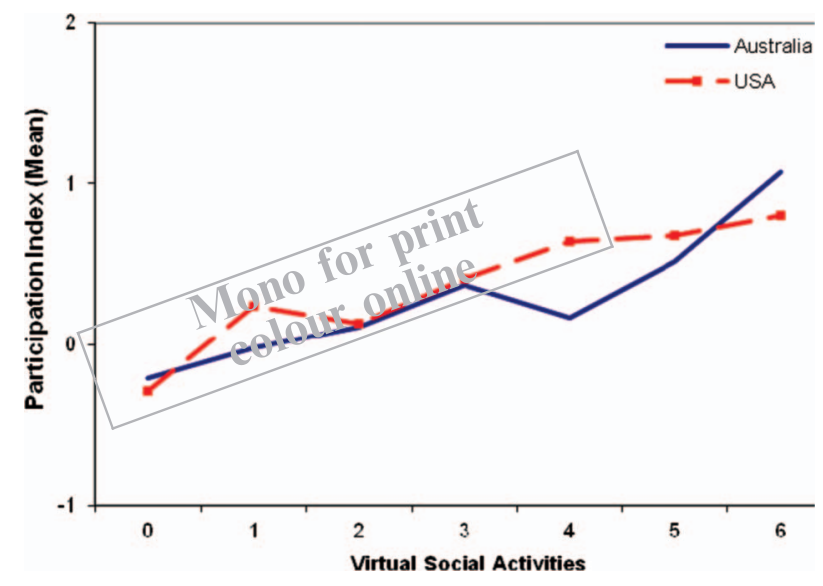

Figure 2. The Relationship between Virtual Social Activity and Participation.

Note: Figure entries are the mean participation scores by the number of virtual social activities. Source: 2005 CID Survey and 2007 Australian Election Study.

\footnotetext{
${ }^{11}$ This index is based on factor scores derived from the first dimension of an un-rotated principal components analysis of the items in Table 4 (we did not include voting because this was not asked in the Australian survey since voting is compulsory). In the US, this first dimension explained 32 per cent of the total variance and all but two items had a factor loading greater than .40. In Australia, the first dimension explains 33 per cent of the total variance and all items had a loading greater than .40 . We did not include general political interest or discussion in the factor analysis.
} 
political activity as spending an evening with a bowling league or choir/choral society.

\section{Multivariate Analyses}

The bivariate relationships for virtual social interactions are a positive indicator that online networking has the potential to create social capital and thereby political participation. Yet before reaching this conclusion we want to probe these relationships more deeply. Cross-sectional public opinion surveys face the challenge of determining whether synchronous correlations between two variables are evidence of a causal relationship - and the direction of the relationship. In addition, there may be spurious relationships with other variables. For instance, more highly educated individuals are more likely to have online skills, and education may produce spurious correlations with political participation. Virtual social activity is also significantly related to age and participation, albeit in different directions.

To address these challenges and compare results across nations, we developed several multiple regression models predicting the summary participation indices developed in the previous section. The first regression model in each nation included a set of standard demographic and attitudinal variables that are routinely linked to political participation (see, for example, Norris 2002a; Verba, Schlozman and Brady 1995). Education was used to tap the impact of

Table 5. Multivariate Regressions to Predict Political Participation

\begin{tabular}{|c|c|c|c|c|c|c|c|c|}
\hline \multirow[b]{2}{*}{ Predictors } & \multicolumn{4}{|c|}{ United States } & \multicolumn{4}{|c|}{ Australia } \\
\hline & Unstd b & $\beta$ & Unstd b & $\beta$ & Unstd $b$ & $\beta$ & Unstd $b$ & $\beta$ \\
\hline Virtual social activity & $\begin{array}{l}.170^{*} \\
(.016)\end{array}$ & $.33^{*}$ & $\begin{array}{l}.139 * \\
(.014)\end{array}$ & $.27 *$ & $\begin{array}{l}.153 \\
(.016)\end{array}$ & $.28 *$ & $\begin{array}{l}.138^{*} \\
(.015)\end{array}$ & $.23 *$ \\
\hline Education & $\begin{array}{l}.230^{*} \\
(.029)\end{array}$ & $.25^{*}$ & $\begin{array}{l}.153^{*} \\
(.026)\end{array}$ & $.17 *$ & $\begin{array}{l}.003 \\
(.002)\end{array}$ & .04 & $\begin{array}{l}.001 \\
(.002)\end{array}$ & .01 \\
\hline Age & $\begin{array}{l}.005^{*} \\
(.002)\end{array}$ & $.09^{*}$ & $\begin{array}{l}.030 \\
(.016)\end{array}$ & .05 & $\begin{array}{l}.003 \\
(.002)\end{array}$ & .05 & $\begin{array}{r}-.002 \\
(.002)\end{array}$ & -.04 \\
\hline African-American & $\begin{array}{l}.009 \\
(.095)\end{array}$ & .00 & $\begin{array}{l}.060 \\
(.083)\end{array}$ & .02 & & & & \\
\hline Hispanic & $\begin{array}{l}.202 * \\
(.093)\end{array}$ & $.07 *$ & $\begin{array}{r}-.049 \\
(.082)\end{array}$ & -.02 & & & & \\
\hline Gender (Female) & $\begin{array}{c}-.160 * \\
(.059)\end{array}$ & $-.08 *$ & $\begin{array}{r}-.067 \\
(.052)\end{array}$ & -.03 & $\begin{array}{r}-.058 \\
(.056)\end{array}$ & -.03 & $\begin{array}{c}-.082 \\
(.046)\end{array}$ & -.04 \\
\hline Left/Right placement & $\begin{array}{r}-.014 \\
(.013)\end{array}$ & -.03 & $\begin{array}{c}-.021 \\
(.011)\end{array}$ & -.05 & $\begin{array}{l}.064^{*} \\
(.013)\end{array}$ & $.14^{*}$ & $\begin{array}{l}.054^{*} \\
(.011)\end{array}$ & $.12 *$ \\
\hline Political interest & & $\begin{array}{l}.489 * \\
(.030)\end{array}$ & $.44 *$ & & $\begin{array}{l}.577^{*} \\
(.030)\end{array}$ & $.45^{*}$ & & \\
\hline Constant & $.674 *$ & $.646^{*}$ & -.008 & 1.147 & & & & \\
\hline Multiple R & .47 & .63 & .31 & .54 & & & & \\
\hline
\end{tabular}

Note: Table entries are coefficients predicting an index of overall political participation based on OLS regressions, standard errors in parentheses. The virtual social activity index is for the entire public and not just Internet users. Coefficients significant at the .05 level are denoted by an asterisk.

Source: 2005 CID Survey and 2007 AES. 
social status on political participation, and control for the pattern of higher online networking by the better educated. For similar reasons, we included age in the regression model to control for general differences in virtual activity and political participation across age groups. In addition, we added gender and leftright ideology to the basic model to control for these possibly spurious effects, and ethnicity in the US study.

The first column for the US and Australia in Table 5 presents this baseline multivariate model. Even in these multivariate analyses, virtual activity is the strongest predictor of overall political participation in both nations. In the US, only education rivals the impact of virtual social interaction. We obtain comparable results for Australia, with very similar standardised and unstandardised coefficients despite the different examples of participation in both nations. The standardised coefficients for both nations are very similar to the simple Pearson $r$ correlation in Table 4, which implies that the bivariate relationship displayed in Figure 2 is little changed after adding multivariate controls. So the basic relationship between virtual networking and participation is not spuriously due to these other control variables.

A more complex question is whether the politically engaged have traits that lead them to be active in virtual social networking (as well as participation in traditional social groups). This implies the causal process runs from political interest to social networking. We cannot solve this causal puzzle, but we did a further test to discount this possibility. We added general political interest to our baseline model of political participation. In a sense, this 'overcontrols' for such a spurious relationship because we have theorised that interest is at least partially dependent on virtual social interactions. Political interest is also produced by other causal processes independent of virtual social interaction, and these are thereby controlled by including interest in the multivariate model.

The second column for the US and Australia in Table 5 presents this expanded multivariate model. Political interest does have a strong relationship with overall political participation in both nations as we should expect; it is psychologically very proximate to the decision to participate. Yet even including political interest in our model has only a modest impact on the coefficient for virtual social activity. Virtual activity is still a strong predictor of participation among Americans and Australians, second only to interest in politics.

In summary, rather than virtual social interactions luring individuals away from active democratic citizenship as some critics have claimed, social networking and similar virtual activities appear to encourage political involvement. Furthermore, the US survey included a question on participation in an extensive list of traditional in-person social groups. Virtual social activity is a significant predictor of participation among Americans even after controlling for traditional social group activity (Kittilson and Dalton 2011). The social interaction that occurs online thus appears to have many of the political benefits of various forms of in-person engagement.

\section{Conclusions}

Many scholars have lamented the decline of civic engagement and social capital in Western democracies, claiming that too many of us are sitting at home in 
front of our televisions sets or our computer monitors, and not personally connecting to our fellow citizens (Macedo et al. 2005; Putnam 2000). These doubts about online social activity persist. Leigh quotes the American social scientist, Norman Nie, to summarise his views: 'The Internet could be the ultimate isolating technology that further reduces our participation in communities even more than did automobiles and television before it' (Leigh 2010, 116; also see Gladwell 2010).

The nature of Internet interaction has changed dramatically, however, with new innovations such as social networking sites, online multiplayer games, blogs and other interactive sites. The Internet once offered only a onedirectional flow of information with minimal interaction with other people. Now it has become a way to connect with others unbounded by geography. This leads us to ask whether virtual social interactions have the same capability as in-person connections to develop social capital.

We examined the extent of social interaction that individuals pursue online. Our findings suggest that the mechanisms through which citizens interact with others are evolving with the new technology of the Internet. More people are looking to their computer monitors or smartphone screens to connect to others in their social groups, others who share their cultural, social or political interests, and to garner information about the world and their fellow citizens through this new medium.

Even if social networking sites cannot completely substitute for in-person social interactions, virtual civil society appears to have many of the same individual benefits for citizen norms and political involvement as traditional civil society activity. Virtual social activity by Americans and Australians is linked to a participatory style of citizenship, first through the norms of political efficacy and engaged citizenship. Second, virtual activity is positively associated with several forms of political engagement. Moreover, these participatory benefits persist even in multivariate analyses controlling for other potential predictors of participation, including general interest in politics. These participation effects are quite substantial and similar for both the US and Australian samples, even though both nations vary considerably in terms of political culture and institutions. This points to the robustness of the participation effects of virtual social activity and the potential generalisability to other advanced industrial democracies.

Not only is virtual civil society expanding, but so is virtual political activity (Mossberger, Tolbert and McNeal 2008; Oates, Owen and Gibson 2006; Smith et al. 2009). The majority of messages that members of Congress receive from their constituents now come in the form of email. The 2008 Obama campaign demonstrated how Internet-based fundraising and voter mobilisation can transform the nature of presidential elections. Internet campaigning is also expanding in Australia (McAllister 2011). Thus, as these Internet-based forms of political activity grow, they facilitate the potential of Internet-based social networks to become politically engaged.

Furthermore, virtual social activity creates a new potential for social capital formation among the young. The greater use of social networking, online discussions and similar technologies among the young enables them to connect to their peers in new ways, with the positive effects we demonstrated in this article. If virtual activity continues to expand at current rates, we may see 
experts begin to speculate about the decreasing social connectedness of older citizens.

Having demonstrated these broad patterns, they should encourage more focused analyses on the characteristics of virtual social activity, paralleling previous research on social group membership. One issue is to assess causality. With a cross-section survey we can only demonstrate a correlation, and infer causality, even with our multivariate controls. These relationships should be a starting point for longitudinal and experimental studies that can validate that interactions produce the patterns we described here, much as studies of social group membership have addressed the causality issue through innovative research designs.

We also expect that virtual interaction can change the nature of social networks. For instance, we expect that interactions based on existing social networks, as represented in some of our virtual interaction items, would deepen bonding relationships. In addition, virtual activity can expand beyond immediate personal networks, such as interactions with people from different countries or interactions with strangers, which may generate more bridging relationships. Facebook exchanges with co-workers may add less to existing stocks of social capital than developing new relationships with individuals who share a hobby or social interest. Online networking is also more likely to extend networks beyond an individual's own social or ethnic background. This implies that the benefits of bridging social capital may be relatively greater with virtual networking.

The Internet also seems especially capable of creating new networks unrestrained by geographic proximity, and renewing connections with friends at long distance. Dispersed networks have the potential to unite like-minded citizens; for instance, those sharing a common concern for environmental protection or conversely those opposing government environmental regulations. Virtual networks also expand the potential for transnational activism. But dispersed online interactions may be less effective in building a geographicbased sense of neighbourhood and community that are useful for addressing other collective action needs (Warren 2000). A friendly neighbour may bring over chicken soup when you are ill or watch your house when you are travelling; a fellow World of Warcraft player on another continent is unlikely to do so.

In short, virtual interactions appear to produce weak ties, bridging ties and more dispersed networks, while in-person social group activity generally produces strong, bonding ties and more homogeneous locally based networks (Curtice and Norris 2007; Hampton, Sessions Goulet and Eun 2009; Norris 2002b). Such 'weak ties' are often stressed as the most valuable aspect of social networks (Granovetter 1973), but there are multiple consequences that follow from these different types of interaction. The growth of Internet activity should focus our research on examining these questions of differential social capital formation.

\section{References}

Australian Election Study. 2007. Survey 2007. Australian National University, College of Arts and Social Sciences. Available from: http://www.assda.edu.au/. 
Baumgartner, J. and Morris, J. 2009. MyFaceTube Politics: Social Networking Web Sites and Political Engagement of Young Adults. Social Science Computer Review 25: 319-38.

Boulianne, S. 2009. Does Internet Use Affect Engagement? A Meta-analysis of Research. Political Communication 26: 193-211.

Cox, E. 2002. Australia: Making the Lucky Country. In: R. Putnam, ed. Democracies in Flux. Oxford: Oxford University Press.

Curtice, J. and Norris, P. 2007. Isolates or Socialites? The Social Ties of Internet Users. In: A. Park, ed. British Social Attitudes. London: Sage.

Dalton, R. 2009. The Good Citizen: How the Young are Reshaping American Politics. Washington, DC: CQ Press.

Ellison, N., Steinfield, C. and Lampe, C. 2007. The Benefits of Facebook 'Friends': Social Capital and College Students' Use of Online Social Network Sites. Journal of Computer-Mediated Communication 12: 1143-68.

Gibson, R. and McAllister, I. 2009. Virtual Social Capital, Political Attitudes and Political Participation. Paper presented at the annual meeting of the American Political Science Association, Toronto, Canada.

Gladwell, M. 2010. Small Change: Why the Revolution will not be Tweeted. New Yorker, 4 October.

Granovetter, M. 1973. The Strength of Weak Ties. American Journal of Sociology 78: 136080.

Hampton, K., Sessions Goulet, L. and Eun, J.H. 2009. Social Isolation and New Technology. Pew Internet and American Life Center. Available from: http://www.pewinternet.org Accessed 10 November 2011.

Hampton, K., Sessions Goulet, L., Rainie, L. and Purcell, K. 2011. Social Networking Sites and Our Lives. Pew Internet and American Life Center. Available from: http://www.pewinternet. org Accessed 10 November 2011.

Ho, S. and McLeod, D. 2008. Social-Psychological Influences on Opinion Expression in Face-to-face and Computer-mediated Communication. Communication Research 35: 190207.

Howard, M.M. and Gilbert, L. 2008. A Cross-national Comparison of the Internal Effects of Participation in Voluntary Organizations. Political Studies 56: 12-32.

Inglehart, R. 1990. Culture Shift in Advanced Industrial Societies. Princeton, NJ: Princeton University Press.

Jenkins, H. 2006. Convergence Culture. New York: New York University Press.

Jennings, M.K. and Zeitner, V. 2003. Internet Use and Civic Engagement: A Longitudinal Analysis. Public Opinion Quarterly 67: 311-34.

Kittilson, M. and Dalton, R. 2008. The Internet and Virtual Civil Society. Research Paper, Center for the Study of Democracy. Available from: http://escholarship.org/uc/item/2cjlc67k Accessed 10 November 2011.

Kittilson, M. and Dalton, R. 2011. Virtual Civil Society: The New Frontier of Social Capital? Political Behavior 33: 625-44.

Kraut, R., Kiesler, S., Boneva, B., Cummings, J., Helgeson, V. and Crawford, A. 2002. Internet Paradox Revisited. Journal of Social Issues 58: 49-74.

Kraut, R., Patterson, M., Lundmark, V., Kiesler, S., Mukophadhyay, T. and Scherlis, W. 1998. Internet Paradox: A Social Technology that Reduces Social Involvement and Psychological Well-being? American Psychologist 53: 1017-32.

Krueger, B. 2002. Assessing the Potential of Internet Political Participation in the United States: A Resource Approach. American Politics Research 30: 476-98.

Leigh, A. 2010. Disconnected. Sydney: University of New South Wales Press.

Macedo, S. et al. 2005. Democracy at Risk. Washington, DC: Brookings.

McAllister, I. 2011. The Australian Voter: 50 Years of Change. Sydney: University of New South Wales.

McKenna, K. and Bargh, J. 2000. Plan 9 from Cyberspace: The Implications of the Internet for Personality and Social Psychology. Personality and Social Psychology Review 4: $57-75$.

Mossberger, K., Tolbert, C. and McNeal, R. 2008. Digital Citizenship: The Internet, Society and Participation. Cambridge, MA: MIT Press.

Newton, K. 1997. Social Capital and Democracy. American Behavioral Scientist 40: 575-86.

Nie, N. and Erbring, L. 2002. Internet and Society: A Preliminary Report. IT \& Society 1: 27583 .

Norris. P. 2002a. The Democratic Phoenix. Cambridge: Cambridge University Press.

Norris, P. 2002b. The Bridging and Bonding Role of Online Communities. International Journal of Press/Politics 7(3): 3-13.

Oates, S., Owen, D. and Gibson, R., eds. 2006. The Internet and Politics: Citizens, Voters and Activists. London: Routledge. 
Pew Research Center. 2010. Pew Internet and American Life Project. Available from: http:// www.pewinternet.org/trends.asp Accessed 10 November 2011.

Putnam, R. 1993. Making Democracy Work. Princeton, NJ: Princeton University Press.

Putnam, R. 2000. Bowling Alone: The Collapse and Renewal of American Community. New York: Simon \& Schuster.

Putnam, R., ed. 2002. Democracies in Flux: The Evolution of Social Capital in Contemporary Society. Oxford: Oxford University Press.

Putnam, R., Feldstein, L. and Cohen, D. 2003. Better Together: Restoring the American Community. New York: Simon \& Schuster.

Shah, D., Schmierbach, M., Hawkins, J., Espino, R. and J. Donavan. 2002. Nonrecursive Models of Internet Use and Community Engagement: Questioning Whether Time Spent Online Erodes Social Capital. Journalism \& Mass Communication Quarterly 79: 964-87.

Smith, A., Schlozman, K., Verba, S. and Brady, H. 2009. The Internet and Civic Engagement. Pew Internet and American Life Project. Available from: http://www.pewinternet.org/Reports/ 2009/15--The-Internet-and-Civic-Engagement.aspx Accessed 10 November 2011.

Stone, W. and Hughes, J. 2002. Social Capital: Empirical Meaning and Measurement Validity. Australian Institute of Family Studies, research paper 47. Available from: http://www.aifs. gov.au/institute/pubs/stone2.html Accessed 10 November 2011.

Tolbert, C. and McNeal, R. 2003. Unravelling the Effects of the Internet on Political Participation? Political Research Quarterly 56: 175-85.

Uslaner, E. 1998. Democracy and Social Capital. In: M. Warren, ed. Democracy and Trust. Cambridge: Cambridge University Press.

Uslaner, E. 2002. The Moral Foundations of Trust. New York: Cambridge University Press.

Valenzuela, S., Park, N. and Kee, K. 2009. Is There Social Capital in a Social Network Site? Facebook Use and College Students' Life Satisfaction, Trust and Participation. Journal of Computer-Mediated Communication 14: 875-901.

van Deth, J., Montero, R. and Westholm, A., eds. 2007. Citizenship and Involvement in European Democracies. London: Routledge.

Verba, S., Schlozman, K. and Brady, H. 1995. Voice and Equality: Civic Voluntarism in American Politics. Cambridge, MA: Harvard University Press.

Warren, M. 2000. Democracy and Association. Princeton, NJ: Princeton University Press.

World Values Survey. Available from: http://www.worldvaluessurvey.org Accessed 10 November 2011.

Zmerli, S. 2010. Social Capital and Norms of Citizenship: An Ambiguous Relationship? American Behavioral Scientist 53: 657-76. 